\title{
Oral Appliances for Sleep Breathing Disorders
}

\author{
Dennis R. Bailey ${ }^{1}$
}

Published online: 19 May 2016

(C) Springer International Publishing AG 2016

\begin{abstract}
Oral appliances gained acceptance over the last decade and, at the same time, have been proven to be an effective way to manage sleep breathing disorders. Their role has become more acceptable since the first practice parameters paper was published in 1995. Over a 10-year period since then, they have gained an even larger and expanded role. This has occurred because of an increased number of articles with a higher level of evidence relative to efficacy, they are more widely recognized by the sleep medicine and physician community, and there are improved outcomes associated with their use. In the future, oral appliances will be more recognized and accepted. This will occur as two key areas emerge in the future: studies that validate the use of oral appliances, including long-term studies, and the role of oral appliances as part of combined therapy with positive airway pressure (PAP) devices.
\end{abstract}

Keywords Oral appliances $\cdot$ Mandibular advancement devices (MADs) · Sleep apnea $\cdot$ Practice parameters $\cdot$ Clinical guidelines $\cdot$ Mandibular advancement $\cdot$ Mean disease alleviation(MDA) · Titration · Vertical opening $\cdot$ Combination therapy

This article is part of the Topical Collection on Sleep Related Breathing Disorders

Dennis R. Bailey

rmc4e@aol.com

1 Orofacial Pain and Dental Sleep Medicine and Sleep Medicine Mini-Residency for Dentists, UCLA School of Dentistry, 8400 E. Prentice Avenue, Suite 804, Greenwood Village, CO 80111, USA

\section{Introduction}

Sleep breathing disorders encompass a wide variety of conditions that may occur during sleep. These range from simply mouth breathing to the more recognized conditions of snoring to sleep apnea. The most common as well as best known management technique has been and continues to be CPAP and other positive airway pressure (PAP) devices. Oral appliances, however, have been utilized in situations where PAP may not be the best option, where the patient desires another option, or where the patient simply cannot tolerate the PAP device. There are many valid studies that demonstrate that oral appliances can be equally effective and, in turn, are better tolerated. Understanding the specifics relative to the action of oral appliances and to the evidence that supports their role in the management of sleep breathing disorders will in the end be of benefit to the patient. When the patient has a choice of therapies, this may result in improved outcomes.

\section{Review of the Practice Parameters for Oral Appliances}

Oral appliances originally were considered more for snoring when they were first used. They were relatively crude and were not well known. In the 1980 s, there were more oral appliances that were made and were available. It was in 1995 that the first practice parameters paper was published in the journal Sleep by the American Academy of Sleep Medicine [1]. This gave rise to the establishment of the first criteria for the use of oral appliances for the management of snoring and sleep apnea. At this time, there was limited evidence regarding their use. The main function of oral appliances was for snoring in the absence of sleep apnea and as 
an alternative for those patients with mild apnea or who were intolerant to CPAP.

In 2006, the original practice parameters paper was reviewed and this resulted in the recognition of more evidence supporting the use of oral appliances in an expanded role [2]. Oral appliances now were for snoring in the absence of sleep apnea but, more importantly, were recognized as an option for patients with mild to moderate sleep apnea. In addition, they were also recognized as a reasonable alternative for those patients who were unable to tolerate PAP devices or who had failed surgery.

Recently, a clinical practice guideline was published that reviewed the most current evidence regarding the use of oral appliances [3•]. This paper did not significantly alter the criteria for the use of oral appliances, but it did provide better evidence regarding the use of oral appliances and it spelled out more specific recommendations regarding the use of oral appliances from both the medical and dental perspectives. The most important recommendation in the guideline is recommendation $4.2 \mathrm{~b}$. This states that oral appliances should be recommended rather than no treatment for patients (adults) with obstructive sleep apnea who cannot tolerate CPAP or who "prefer alternate therapy".

In 2013, Dr. Schmidt-Nowara published a commentary that recommended that patients be involved in the selection of their treatment [4]. The recommendation is based on the fact that the majority of patients diagnosed with a sleep breathing disorder are not severe; thus, based on the current evidence, an oral appliance is an appropriate option for them. In addition, the public is now better informed about available choices, as he put it "empowered" so they are looking for the best personal option. Also, reimbursement has improved and continues to do so and the number of dentists involved in providing this therapy is also increasing.

Another topic of concern is the determination of who is qualified to provide oral appliance therapy. The clinical practice guideline addresses this by stating that certain criteria need to be followed as established by the American Academy of Dental Sleep Medicine (AADSM). This involves a variety of avenues for being considered as qualified. These include certification by a non-profit organization, such as a program in a dental school, becoming the dental director of a dental sleep medicine facility, or by taking at least 25 hours of education specifically in dental sleep medicine. The recommendations from this guideline paper for the use of oral appliances are summarized in Table 1.

\section{Mechanisms of Action}

Mandibular repositioning is designed to open the airway by advancing the mandible and the tongue base so that during sleep they are less capable of occluding the airway. However, it is not exclusively done by advancement. There is a certain degree of vertical opening that contributes to their success. To what degree this vertical opening plays a role has not been studied extensively. One article recently looked at raising the vertical without any mandibular advancement and found that vertical opening alone may actually worsen the apneahypopnea index (AHI) [5]. One study looked at vertical opening; however, only two measurements of vertical were considered, 4 and $14 \mathrm{~mm}$, with similar degrees of mandibular advancement [6]. It was further reported that patients preferred a lesser degree of vertical opening. In reality, $14 \mathrm{~mm}$ of vertical opening is excessive. I have found that often times opening the bite vertically as opposed to simply advancing the mandible on the horizontal has been equally successful in improving the effectiveness. Typically, the vertical is between 5 and $7 \mathrm{~mm}$ of the inter-incisal distance (measured as the distance between the incisal edges of the maxillary and mandibular anterior teeth (incisors) at or near the midline). It must be understood that with any amount of advancement, there has to be some degree of vertical opening as well. In like manner if the titration of the oral appliance is going to focus on vertical opening, then a small degree of advancement must accompany that opening based on the arc of mandibular movement associated with this vertical change. In addition, the amount of vertical opening cannot be such that it leads to an inadequate lip seal and the potential for more mouth breathing. The theory is that this vertical opening improves the amount of tongue space and hence lessens the ability of the tongue to fall back into the oropharyngeal airway.

Mandibular advancement has been the main focus of the treatment. The difficulty is that the amount of advancement is variable and individualized for each patient. There is no standard or absolute for the degree of mandibular advancement either at the start of the treatment or for the titration of the oral appliance [7]. Oral appliances are proposed to work through a combination of opening of the airway, or what might be termed airway dilation, and the stabilization of the mandible and tongue such that it is more difficult for them to collapse back into the airway space. It is proposed that without the oral appliance, the airway is somewhat restricted, and with the oral appliance, there is improvement in airway caliber, thus reducing the tendency to collapse.

\section{The Role and Management of the Tongue}

The tongue, and particularly the tongue base, has been the major area of concern as it relates to airway compromise associated with sleep breathing disorders. The tongue has been termed a muscular hydrostat [8]. It is made up of more than just the genioglossus muscle and, as such, can take on many shapes and form. It can move in many ways so exercises designed to position the tongue can actually improve the airway and reduce many of the signs and symptoms of a sleep 
Table 1 Clinical practice guidelines for oral appliance therapy for obstructive sleep apnea

\begin{tabular}{lc}
\hline Recommendations & Grade \\
\hline $\begin{array}{l}\text { Sleep physicians prescribe oral appliances as opposed to not therapy for those that snore and apnea } \\
\text { has been ruled out }\end{array}$ & Standard \\
A qualified dentist should provide the oral appliance when prescribed by a sleep physician and a & Guideline \\
diagnosis of sleep apnea has been made & \\
$\begin{array}{l}\text { Oral appliance should be prescribed by the sleep physician as opposed to not treatment for adults } \\
\text { with sleep apnea. Applies to those who do not tolerate CPAP or are seeking an alternative }\end{array}$ & Standard \\
$\begin{array}{l}\text { Qualified dentists should provide "oversight" when an oral appliance is used. This is to manage } \\
\text { outcomes, reduce their incidence (side effects), and monitor for occlusal (bite) changes }\end{array}$ & Guideline \\
$\begin{array}{l}\text { Sleep physician should do follow-up testing to determine outcomes (efficacy) of the oral appliance } \\
\text { Ongoing follow-up (periodic visits should be done by the qualified dentist and the sleep physician) }\end{array}$ & Guideline \\
\hline
\end{tabular}

breathing disorder $[9,10]$. These exercises are termed myofunctional or oropharyngeal tongue exercises. The current research has shown that these exercises, when done independently, also have an impact on the management of sleep apnea (reduced Epworth Sleepiness Scale score, improved AHI, and improvement in quality of life). The theory is that these exercises, when done during the daytime, become learned and, as such, carry over into and during the time of sleep.

\section{The Role of the Nasal Airway}

The role of the nasal airway associated with breathing is not addressed at the level that it should be. The purpose of the nose and nasal breathing is well understood [11]. However, it is not a priority when it comes to improved outcomes for oral appliance therapy as well as for PAP devices.

The general purpose of the nasal airway is to improve the quality of the air one breathes. The nose has been termed the carburetor of the body. Its function is to warm and humidify the air [12]. When the patient is a chronic mouth breather, the quality of the inspired air is reduced; hence, the blood oxygen levels may be less than the optimum. Nasal airway resistance has been shown to negatively impact the success of oral appliance therapy $[13 \bullet \bullet]$. Hence, reduced nasal resistance may be beneficial in improved outcomes with the use of an oral appliance. Because of this, steps need to be taken to improve the nasal airway. These may consist of addressing any allergies, nasal dilation whereby the nasal valve is improved, and nasal irrigation.

\section{Current Status of Oral Appliances}

\section{Mean Disease Alleviation}

Recently, Vanderveken et al. had proposed a method that evaluates the outcome of oral appliances as well as CPAP based on the relationship between efficacy and compliance that is termed mean disease alleviation (MDA) [14••]. Efficacy is based on the reduction of the AHI, and compliance is related to the number of hours of the use of either the oral appliance or the CPAP. The MDA is measured by a percentage. What has been found is that the oral appliance and the CPAP are nearly equivalent in outcomes. This concept is in line with what most of the current studies show as it relates to the comparisons of the oral appliance and PAP devices based on hours of use and their relative effectiveness.

At this time, the development of compliance monitors that can be used with an oral appliance is developing [14*0]. They are currently available on a limited basis, and at this time, only one is being utilized. These are thermal sensitive devices that can measure hours of use of an oral appliance. The limitation of these devices is that unlike PAP monitoring devices, these are not able to measure any of the parameters of sleep such as oxygen saturation, oxygen nadir, or AHI.

\section{Oral Appliances for Sleep Breathing Disorders}

At this time, the literature that addresses oral appliances is mainly focused on their role as it relates to CPAP. Since PAP devices are considered the gold standard, how oral appliances measure up or relate to them is a major focus. A significant review paper on oral appliances dates back to 2007 [15]. In this article, it was concluded that oral appliances, although not as effective as CPAP, were actually better than UPPP surgery and had a definite role as a means to treat snoring and sleep apnea.

A comparison of oral appliances to CPAP showed that oral appliances were similar to CPAP in lowering the AHI to less than 5 [16]. This study determined that oral appliances were very effective; however, the CPAP was more effective in those with moderate to severe sleep apnea.

Recently, the literature is finding very similar results: the use of the oral appliance in terms of hours per night is much greater than a PAP device, yet the impact on the apnea in most cases is improved more with the PAP device especially as it relates to the more severe patients. The comparison of oral appliances to CPAP as it relates to adherence and the hours of use has demonstrated that oral appliances have a greater 
degree of adherence. The improved adherence found with oral appliances is believed to result in improved treatment because the oral appliance is typically worn for longer periods of time during the night than CPAP is typically used or worn $[17 \bullet \bullet, 18$, 19]. In addition, it has been found that oral appliances that are adjustable provide improved outcomes as compared to oral appliances that are not adjustable $[20,21]$.

\section{Oral Appliances Impact on Health and Medical Conditions}

Oral appliances have been shown to have an impact similar to PAP devices on a variety of medical conditions. A recent study showed that oral appliances and CPAP have a similar effect on blood pressure [22••]. This was a meta-analysis which determined that there was no statistical difference in blood pressure outcomes as it relates to CPAP or oral appliances. Another study reports that health outcomes, comprised of blood pressure, quality of life, and subjective sleepiness, were all improved with an oral appliance when compared to CPAP [17••]. The results reported after 1 month showed similar results with both forms of treatment; however, oral appliances were superior to CPAP as it relates to quality of life. A meta-analysis recently also shows that oral appliances are effective in improved blood pressure control in patients with mild to moderate sleep apnea [23]. It appears that even a modest reduction in the blood pressure may result in a lower risk for stroke and coronary artery disease. This study also indicates that the effect of the oral appliance is not specific to one type of oral appliance but seems to apply generically to most oral appliances.

As it relates to cardiovascular disease, oral appliances and CPAP were found to be equivalent in reducing the risk for fatal events in patients with severe sleep apnea [24]. The report indicates that when there is adequate treatment, both oral appliances and CPAP show a reduction in both fatal and nonfatal cardiovascular events. These results are linked to the reduction in the blood pressure. In addition, despite the fact that oral appliances did not result in a similar improvement or normalization of the polysomnographic indices, the use of the oral appliance was similar to CPAP in reducing cardiovascular mortality. This was also related to the improved adherence to treatment with the oral appliances as compared to CPAP.

\section{Combination Therapy: Oral Appliance with PAP Device}

The use of the oral appliance in combination with the PAP device has the potential of improving the management of the apnea along with far better adherence. At the APSS sleep meeting in Seattle in June of 2015, Vanderveken presented data at that meeting as it relates to mean disease alleviation. It was disclosed that with an oral appliance or CPAP, the results were about equal. However, with the two in combination, the results were significantly improved.

It has been reported that combination therapy, not just oral appliances with PAP devices, but oral appliances with positional therapy are also more effective at improving the desired result $[25 \bullet \bullet]$. The combination of various available treatment modalities may help to produce more of a long-term outcome. Another study reported that the use of a tongue positioner, also known as a tongue retainer, can be beneficial when used in combination with CPAP [26]. In this case report, it was found that this appliance improved the airway space and the patient's respiration and the sleep efficiency was improved all with an associated reduction in the nasal CPAP (nCPAP). The data demonstrates a reduction in the AHI from a baseline of 24.1 to 16.2 with the oral appliance. With the nCPAP, the AHI was 8.4, and with the two in combination, the AHI was 2.3. The nCPAP was reduced from 13.5 to 10.1. A study in 2011 demonstrated that with the combined use of an oral appliance with CPAP, the pressures were reduced significantly and, at the same time, the AHI become lower [27]. My personal experience with multiple patients has resulted in CPAPs being reduced by $50 \%$ or more with an improved result.

\section{A Case Report}

Patient A presented a number of years ago to investigate obtaining an oral appliance to manage his moderate to severe sleep apnea. He had been using CPAP and was interested in obtaining an oral appliance as an alternative or at least to use when he traveled on business. He had been doing well with the CPAP; however, the pressure was at 13 . This pressure was at times an issue. He obtained the oral appliance and found it did not work quite as well as the CPAP when he was at home but was adequate as a substitute when he was traveling, which he did frequently. He returned to the sleep center and had overnight testing with the oral appliance, and it was determined that it did not perform as well as the CPAP. However, when he used the two in combination, the CPAP was reduced to 5 and his AHI was 1 .

\section{Future Considerations}

There are a number of considerations that need to be considered. These are as follows:

- How much does an improved nasal airway impact the efficacy of the oral appliance?

- For patients with more severe apnea, is combination therapy something that should be embraced more by the dentist and sleep physician? 
- How can "qualified dentists" who provide oral appliance therapy be better identified given the number of different groups claiming to be authorities in this field?

\section{Conclusion}

Numerous studies, as has been described, have continuously indicated that the oral appliances have a positive effect on sleep breathing disorders because of their improved adherence as it relates to CPAP. CPAP certainly demonstrates improved outcomes particularly related to the more severe patient. The missing link may very well be the level of expertise of the dentist providing this care. This is why the need to identify the qualified dentist is so important. Ultimately, the patient who chooses an oral appliance will benefit from this therapy if the person delivering the treatment is well trained.

Other issues that need to be addressed are studies that support the use of oral appliances and long-term studies to objectively support their use. This would no doubt include the use of monitoring devices that can substantiate adherence. Probably the most important is the development of a common agreement about the follow-up testing that should be done and at what time frame. Given that oral appliances work differently compared to PAP devices, it can take time, often 6 months or more, to objectively determine that an oral appliance is effective.

Regardless, oral appliances over the last 10 to 20 years have demonstrated that they are an effective option for many who desire this as the treatment of choice. More recently, the option and acceptance of combination therapy may add additional benefit and improved outcomes in the future.

\section{Compliance with Ethical Standards}

Conflict of Interest Dennis R. Bailey does not have any conflicts of interest.

Human and Animal Rights and Informed Consent This article does not contain any studies with human or animal subjects performed by any of the authors.

\section{References}

Papers of particular interest, published recently, have been highlighted as:

- Of importance

•. Of major importance

1. Thorpy M, Chesson A, Derderian S, Kader G, Millman R, Potolicchio $\mathrm{S}$, et al. Practice parameters for the treatment of snoring and obstructive sleep apnea with oral appliances. Sleep. 1995;18(6):511-3.
2. Kushida C, Morgenthaler TI, Littner MR, Alessi CA, Bailey D, Coleman J, et al. Practice parameters for the treatment of snoring and obstructive sleep apnea with oral appliances: an update for 2005. Sleep. 2006;29(2):240-3.

3. Ramar K, Dort LC, Katz S, Lettieri CJ, Harrod CG, Thomas SM, et al. Clinical practice guideline for the treatment of obstructive sleep apnea and snoring with oral appliance therapy: an update for 2015. J Clin Sleep Med. 2015;11(7):773-827. It is appropriate for any dentist who does oral appliances and all sleep physicians as well as other physicians who refer patients for oral appliance therapy to become familiar with the content of this guideline.

4. Schmidt-Nowara W. Preferred treatment (commentary). J Clin Sleep Med. 2013;9:319-24.

5. Nikolopoulou M, Naeije M, Aarab G, Hamburger HL, Visscher $\mathrm{CM}$, Lobbezoo F. The effect of raising the bite without mandibular protrusion on obstructive sleep apnea. J Oral Rehabil. 2011;38: 643-7.

6. Pitsis AJ, Darendeliler MA, Gotsopoulos H, Petocz P, Cistulli PA. Effect of vertical dimension on efficacy of oral appliance therapy in obstructive sleep apnea. Am J Respir Crit Care Med. 2002;166: $860-4$.

7. Dieltjens M, Vanderveken OM, Heyning PH, Braem MJ. Current opinions and clinical practice in the titration of oral appliances in the treatment of sleep-disordered breathing. Sleep Med Rev. 2012;16:177-85.

8. Zaidi FN, Meadows P, Jacobowitz O, Davidson TM. Tongue anatomy and physiology, the scientific basis for a novel targeted neurostimulation system designed for the treatment of obstructive sleep apnea. Neuromodulation. 2012.

9. Camacho M, Certal V, Abdullatif J, Zaghi S, Ruoff C, Capasso R, et al. Myofunctional therapy to treat obstructive sleep apnea: a systematic review and meta-analysis. Sleep. 2015;38(5):669-75.

10. Cooper A. Orofacial myology and myofunctional therapy for sleep related breathing disorders. Sleep Med Clin. 2010;5:109-13.

11. Pevernagie DA, De Meyer MM, Claeys S. Sleep, breathing and the nose. Sleep Med Rev. 2005;9:437-51.

12. Naclerio RM, Pinto J, Assanasen P, Baroody FM. Observations on the ability of the nose to warm and humidify inspired air. Rhinology. 2007;45(2):102-11.

13.• Zeng B, Ng AT, Qian J, Petocz P, Darendeliler MA, Cistulli PA. Influence of nasal resistance on oral appliance outcome in obstructive sleep apnea. Sleep. 2008;31(4):543-7. In order for any therapy, especially oral appliances and CPAP, to be successful, the provider needs to be aware of the role of the nasal airway and how to evaluate it.

14.• Vanderveken OM, Dieltjens M, Wouters K, De Backer WA, Van de Heyning PH, Braem MJ. Objective measurement of compliance during oral appliance therapy for sleep-disordered breathing. Thorax. 2013;68:91-6. It is necessary that the use of compliance monitors be well understood. In addition, the concept of mean disease alleviation (MDA) is a new way to assess the impact of treatment.

15. Hoffstein V. Review of oral appliances for treatment of sleepdisordered breathing. Sleep Breath. 2007;11:1-22.

16. Holley AB, Lettieri CJ, Shah AA. Efficacy of an adjustable oral appliance and comparison with continuous positive airway pressure for the treatment of obstructive sleep apnea syndrome. Chest. 2011;140(6):1511-6.

17.• Phillips CL, Grunstein RR, Darendeliler MA, Mihailidou AS, Srinivasan VK, Yee BJ, et al. Health outcomes of continuous positive airway pressure versus oral appliance treatment for obstructive sleep apnea. Am J Respir Crit Care Med. 2013;187(8):879-87. Despite this being a study that looks at outcomes after only 1 year, the evidence is very compelling that oral appliances have the potential to be equally effective. 
18. Pliska BT, Almeida F. Effectiveness and outcome of oral appliance therapy. Dent Clin N Am. 2012;56:433-44. In sleep medicine and dentistry.

19. White DP, Shafazand S. Mandibular advancement device vs CPAP in the treatment of obstructive sleep apnea: are equally effective in short term outcomes? Commentary. J Clin Sleep Med. 2013;9(9): 971-2.

20. Littieri CJ, Paolino N, Eliasson AH, Shah AA, Holley AB. Comparison of adjustable and fixed oral appliances for the treatment of obstructive sleep apnea. J Clin Sleep Med. 2011;7(5):43945 .

21. Almeida FR. Complexity and efficacy of mandibular advancement splints: understanding their mode of action. Commentary. J Clin Sleep Med. 2011;7(5):447-8.

22.• Bratton DJ, Gaisl T, Wons AM, Kohler M. CPAP vs mandibular advancement devices and blood pressure in patients with obstructive sleep apnea: a systematic review and meta-analysis. JAMA. 2015;314(21):2280-93. This study points out that oral appliance therapy may very well impact one of the health concerns related to sleep apnea and that the appliance may very well have an impact on blood pressure.
23. Ifikhar IH, Hays ER, Iverson M-A, Magalang UJ, Maas AK. Effect of oral appliances on blood pressure in obstructive sleep apnea: a systematic review and meta-analysis. J Clin Sleep Med. 2013;13(9):165-74.

24. Anandam A, Patil M, Akinnusi M, Jaoude P, El-Solh AA. Cardiovascular mortality in obstructive sleep apnoea treated with continuous positive airway pressure or oral appliance: an observational study. Respirology. 2013;18:1184-90.

25.• Vanderveken OM. Combination therapy for obstructive sleep apnea in order to achieve complete disease alleviation: from taboo to new standard of care. Editorial. J Dent Sleep Med. 2015;2(1):7-8. Combination therapy is very underutilized and even worse rarely considered. This concept needs to be given more consideration for improved patient care as well as improved outcomes.

26. Ciavarella D, Sabato R, Battista G, Muzio LL, Campisi G, Cassano $\mathrm{M}$, et al. Effects of the association of nCPAP and tongue positioner device in OSAS treatment: a case report. J of Dent Sleep Med. 2014;1(1):21-3.

27. Ali A, Moitheennazima B, Akinnusi ME, Churder PM, Lafornara AM. Combined oral appliance and positive airway pressure therapy for obstructive sleep apnea: a pilot study. Sleep Breath. 2011;15:203-8. 